\title{
A clinic based survey of blindness and eye disease in Cambodia
}

Ian Thomson

\begin{abstract}
Aims-To survey the spectrum of eye disease presenting to rural eye clinics in Cambodia.

Methods-A total of 1381 patients seen consecutively at 13 eye clinics were examined and the findings recorded.

Results-231 (16.7\%) were bilaterally blind (visual acuity $<3 / 60$ in both eyes); 263 $(19 \%)$ were unilaterally blind, and 169 $(12 \%)$ had low vision (visual acuity $<6 / 18$ in the better eye). Cataract was the commonest cause of visual loss in all three categories and was responsible respectively in $69 \%, 40 \%$, and $55 \%$ of each group. Trachoma was diagnosed in $13 \%$ of patients. Thirty three of them needed lid surgery for trichiasis.

Conclusion-With the difficult practical and political situation in Cambodia there seems little prospect of making substantial inroads into the backlog of avoidable blindness in the near future.

(Br F Ophthalmol 1997;81:578-580)
\end{abstract}

Cambodia lies in South East Asia bordered by Thailand to the west, Laos in the north, Vietnam to the east, and the Gulf of Thailand in the south. The land area is 69898 square miles and the population approximately nine million, $90 \%$ of whom live in the rural areas. The capital city, Phnom Penh, has an estimated population of one million. The country is poor with a per capita gross national product of US $\$ 150.00$, a life expectancy of 51 , and a literacy rate of $35 \%$. The climate is tropical monsoon.

From 1975 to 1979 the country was under the control of the Khmer Rouge led by Pol Pot. During that time an estimated two million Cambodians were executed or starved to death. The educated section of the population was particularly targeted and most of the doctors, nurses, teachers, lawyers, etc were either killed or else managed to flee the country. Cambodia has yet to recover from this horror. Eye care services continue to reflect the lack of

Christian Service Society Eye Hospital, 66 Rupsha Strand Road, Khulna, Bangladesh I Thomson

Correspondence to: I Thomson, 3 Hillgate Street, Terrington St Clement, King's Lynn PE34 4NS.

Accepted for publication 26 March 1997

\section{Patients and methods}

A series of 13 eye clinics was prearranged in the rural areas of the three provinces close to Phnom Penh-Kandal, Kampong Speu, and Takeo. The local people were told via nongovernmental agencies working in the area that an eye team would visit on a particular date. None of the patients was preselected or screened and so may be taken as representative of the spectrum of eye disease presenting to rural eye clinics. The clinics were carried out between 22 April and 10 May 1996.

The visual acuity was measured using an illiterate $\mathrm{E}$ chart by trained auxiliary staff and all patients were then examined by the ophthalmologist (IT). The clinics were open ended in respect of patient numbers and all who attended were seen. Some clinics were busy and some quiet, the smallest number seen being 47 and the highest 300; a total of 1381 patients were dealt with. Basic medicines were provided where appropriate and reading glasses were available for presbyopes. Those whom it was thought would benefit from surgery were referred to Phnom Penh.

\section{Results}

There were 562 male patients and 819 females giving a $M: F$ ratio of $2: 3$.

\section{BILATERAL BLINDNESS}

There were 231 patients who were bilaterally blind. Where the cause was different in each eye the most treatable disease was taken as the cause of blindness. The commonest cause was mature cataract responsible for $69 \%$ of blindness. All 160 patients were thought likely to improve with surgery and were referred to Phnom Penh. Chronic glaucoma was the second commonest cause, diagnosed in 17 patients $(7 \%)$. Four had some residual vision and were referred for drainage surgery. Three of them were children under the age of 9 all of whom were beyond effective treatment.

The other causes are as shown in Table 1.

UNILATERAL BLINDNESS

There were 263 patients who were unilaterally blind. Cataract was again the main cause, being responsible for $40 \%$.

Table 1 Causes of bilateral blindness

\begin{tabular}{lrrrr}
\hline & Female & Male & Total & \multicolumn{1}{c}{$\%$} \\
\hline Cataract & 98 & 62 & 160 & 69.26 \\
Glaucoma & 8 & 9 & 17 & 7.36 \\
Trichiasis/trachoma & 8 & 6 & 14 & 6.06 \\
Aphakia & 6 & 3 & 9 & 3.90 \\
Refractive error & 2 & 2 & 4 & 1.73 \\
Phthisis & 2 & 2 & 4 & 1.73 \\
Optic atrophy & 2 & 2 & 4 & 1.73 \\
Uveitis & 2 & 1 & 3 & 1.30 \\
Retinitis pigmentosa & 2 & 1 & 3 & 1.30 \\
Corneal leucoma & 0 & 3 & 3 & 1.30 \\
Trauma & 1 & 2 & 3 & 1.30 \\
Pterygium & 3 & 0 & 3 & 1.30 \\
Corneal ulcer & 0 & 2 & 2 & 0.87 \\
Corneal dystrophy & 1 & 0 & 1 & 0.43 \\
Dislocated lens & 0 & 1 & 1 & 0.43 \\
Total & 135 & 96 & 231 & 100.00 \\
\hline
\end{tabular}


Table 2 Causes of unilateral blindness

\begin{tabular}{|c|c|c|c|c|}
\hline & Female & Male & Total & $\%$ \\
\hline Cataract & 59 & 48 & 107 & 40.68 \\
\hline Trauma & 14 & 20 & 34 & 12.93 \\
\hline Leucoma & 13 & 8 & 21 & 7.98 \\
\hline Phthisis & 8 & 11 & 19 & 7.22 \\
\hline Glaucoma & 7 & 5 & 12 & 4.56 \\
\hline Pterygium & 6 & 5 & 11 & 4.18 \\
\hline Trichiasis/trachoma & 7 & 2 & 9 & 3.42 \\
\hline Enucleated & 5 & 3 & 8 & 3.04 \\
\hline Corneal ulcer & 3 & 3 & 6 & 2.28 \\
\hline Refractive error & 0 & 6 & 6 & 2.28 \\
\hline Aphakia & 3 & 3 & 6 & 2.28 \\
\hline Optic atrophy & 1 & 4 & 5 & 1.90 \\
\hline Uveitis & 2 & 1 & 3 & 1.14 \\
\hline Tumour & 1 & 1 & 2 & 0.76 \\
\hline Staphyloma & 1 & 1 & 2 & 0.76 \\
\hline Retinoblastoma & 0 & 1 & 1 & 0.38 \\
\hline Endophthalmitis & 0 & 1 & 1 & 0.38 \\
\hline Maculopathy & 1 & 1 & 2 & 0.76 \\
\hline Amblyopia & 1 & 1 & 2 & 0.76 \\
\hline Microcornea & 2 & 0 & 2 & 0.76 \\
\hline Vitritis & 1 & 0 & 1 & 0.38 \\
\hline Dislocated lens & 0 & 1 & 1 & 0.38 \\
\hline Retinal detachment & 1 & 0 & 1 & 0.38 \\
\hline Disciform keratitis & 0 & 1 & 1 & 0.38 \\
\hline Total & 136 & 127 & 263 & 100.00 \\
\hline
\end{tabular}

A definite history of trauma was given by 34 patients (13\%) and it was thought likely that a number of those blind with corneal leucoma, phthisis, and enucleated eyes (48 in all) were also the result of injury.

Cambodia has one of the highest number of unexploded mines of any country in the world with an estimated eight million (approximately one per head of population). One in 300 of the population is an amputee as a result of mine

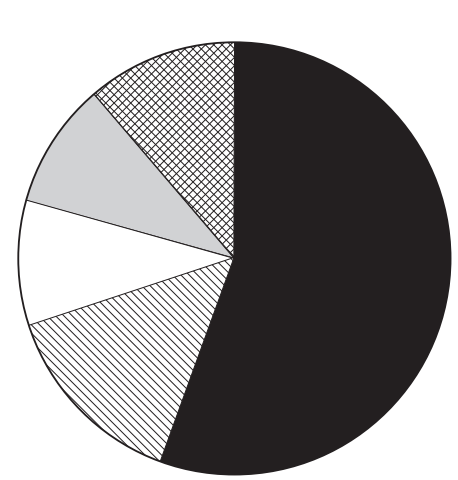

Low vision $\quad \mathrm{n}=169$

Figure 1 Major causes of low vision.

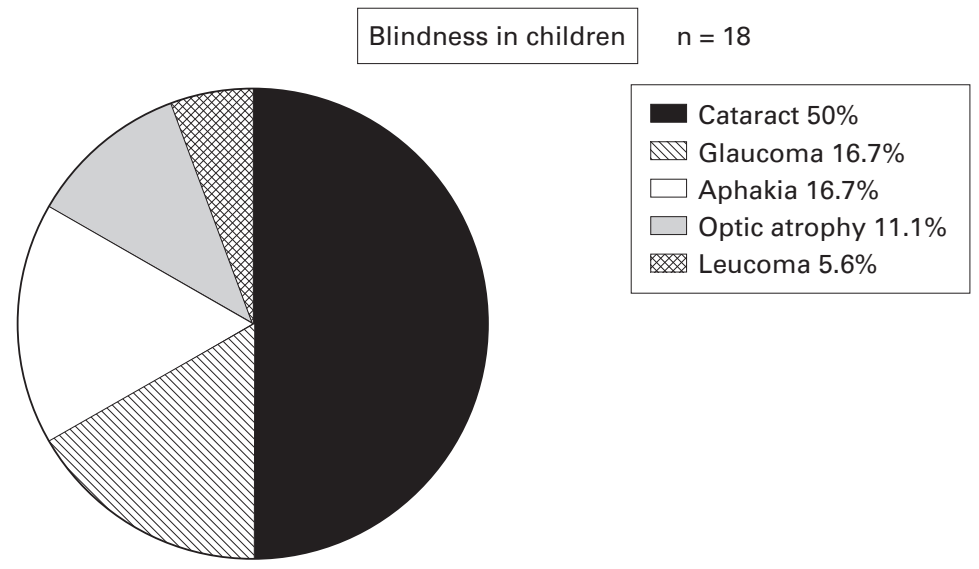

Figure 2 Causes of blindness in children. blasts and eye injury and blindness are a common concomitant finding.

Other causes of unilateral blindness are listed in Table 2 .

LOW VISION

Low vision (visual acuity $<6 / 18$ in the better eye) was found in 169 patients. Most were due to cataract which was seen in 94 patients $(55 \%)$.

The other major causes are shown in Figure 1.

\section{PTERYGIUM}

Pterygium is common and was found in 179 $(13 \%)$ of all patients. It was the cause of low vision in 19 patients, unilateral blindness in 11 patients, and bilateral blindness in three. Pterygium was more than twice as common in women as in men.

TRACHOMA/TRICHIASIS

Trachoma was found in 188 patients $(13.6 \%)$. It was more than twice as common in women as in men with a $M: F$ ratio of $55: 133$. Allowing for the greater number of women in the sample it is still $60 \%$ more common in women.

Trichiasis was found in 33 patients $(2 \%)$, nine men and 24 women. They were referred for lid surgery.

Trachoma, as manifest by trichiasis or trachomatous keratitis, was responsible for $6 \%$ of bilateral blindness, $3 \%$ of unilateral blindness, and $9 \%$ of low vision (Tables 1 and 2 and Fig 1).

REFRACTIVE ERROR AND PRESBYOPIA

Both were common. One hundred and nine patients $(8 \%)$ were referred for refraction, the criteria being vision equal to or less than $6 / 18$ in the better eye and with no other obvious cause of visual loss. Two hundred and ninety three pairs of reading glasses were dispensed.

\section{GLAUCOMA}

Intraocular tensions were not routinely measured. Glaucoma was diagnosed where low vision, as defined, prompted examination of the fundus and subsequently a C:D ratio of $>0.6$ was seen. Using this criterion 32 patients ( $2 \%)$ were thought to have glaucoma; 17 were bilaterally blind and 12 were unilaterally blind. Nine patients were referred for drainage surgery.

No patients with acute angle closure were seen.

EYE DISEASE IN CHILDREN

Eighteen $(20 \%)$ of the 90 children under the age of 16 were bilaterally blind. Congenital cataract was responsible for $50 \%$ (Fig 2).

Vitamin A deficiency (Grade X1A/B conjunctival xerosis and Bitot's spots) was seen in two children.

\section{Discussion}

The limitations of clinic and hospital based surveys are well recognised. The patients attending are self selecting and not necessarily representative of the total population with eye 
disease. The elderly are likely to be underrepresented since decreasing vision is regarded as a normal part of growing old. The very poor may be unable to afford the transport costs involved. Poor vision in the very young may not be recognised. Nevertheless, in the absence of any other information on eye disease in Cambodia and the impracticability of carrying out a population based study in the present unstable conditions such data may give some idea of the eye needs of the country.

The male:female ratio of $2: 3$ is unusual in my experience and similar studies from other developing countries have found the ratio to be the other way round. ${ }^{12}$ It may reflect a real imbalance in the population. In the absence of any up to date census information one can only speculate. Were more men than women executed or died during the Pol Pot terror? One piece of evidence from our figures suggests this may have been so. Under the age of 30 the male:female ratio of the patients we saw was 1:1. Over the age of 30 it falls to 3:5. The present over thirties population would have been in their early teenage years and older during the height of the genocide and more likely to have been killed. Interestingly, the sex ratio is reversed for patients who were found to be aphakic with $M: F=3: 2$. It may be that where there is competition for scarce resources men are still able to come out on top despite being in a minority.

Cambodia is one of the least well served countries in the world for eye care. There is only one fully qualified Cambodian ophthalmologist in clinical practice for the population of over eight million. There are a number of eye doctors in training and some general doctors with eye training doing cataract surgery, often with indifferent results. Three expatriate eye doctors are currently on long term assignments in Cambodia and plan to start an 18 month training course in basic ophthalmology for Cambodian doctors which will include cataract surgery.

Visiting teams of ophthalmologists from Japan, Europe, Australia, and India visit regularly for periods of 3-4 weeks. A generation of doctors was lost during the Pol Pot regime and it will take another generation to replace them.

Present eye work is mainly confined to the two main centres of population, Phnom Penh and Battambang. The $80 \%+$ of the population who live in the rural areas have little or no access to eye care. Large areas of the country are still under the control of the Khmer Rouge and it is not possible to work or travel there. Millions of unexploded landmines pose a constant threat to travel in the countryside.

Given the history of Cambodia and estimating blindness prevalence rates from countries at the same stage of development it is unlikely that the rate will be less than $1 \% .^{3}{ }^{4}$ This would suggest treatable bilateral blindness from cataract alone affecting some 56000 people. From available figures there are fewer than 2000 cataract operations being carried out each year. With an estimated incidence of 8000 new cases per year there seems little prospect of making substantial inroads into the backlog of avoidable blindness in the near future.

I would like to thank Joanna Thomson for collecting the figures, the Maryknoll community and their organisation in Phnom Penh, Rehabilitation of Blind Cambodians, for arranging the clinics and to Christoffel Blindenmission for sending me to Cambodia and providing financial support.

1 Potter AR. Causes of blindness and visual handicap in the Central African Republic. Br F Ophthalmol 1991;75:326-8. 2 Cofie G, Tenkorang J, Thomson I. Blindness in Ghana-a hospital based survey. Commun Eye Health 1991;7:9-10.

3 Faul H, Minassian D, Sowa S, Foster A. A national survey of blindness and low vision in the Gambia. Br f Ophthalmol 1989;73:82-7.

4 Thomson IM, Chumbley LC. Eye disease in the West Bank and Gaza Strip. Br f Ophthalmol 1984;68:598-602. 